\title{
Underwater peroral endoscopic myotomy (U-POEM) after tension capnoperitoneum and capnothorax during POEM
}

Severe peroral endoscopic myotomy (POEM)-related complications are uncommon (about $1.2 \%$ [1]), and $\mathrm{CO}_{2}$-related complications are usually mild. Nevertheless, severe life-threatening complications such as tension capnothorax or capnoperitoneum with hemodynamic and respiratory compromise could develop. Underwater POEM, described by Binmoeller [2], could be used to prevent $\mathrm{CO}_{2}$-related complications.

A 77-year-old man (American Society of Anesthesiologists class IV) with chronic kidney disease requiring hemodialysis, severe chronic obstructive pulmonary disease (COPD, GOLD IV), and other comorbidities presented with severe dysphagia with regurgitation and malnutrition. He had an 8-year history of type 2 achalasia (Eckardt score 10), with previous unsuccessful treatment (three balloon dilations $[40 \mathrm{~mm}$ ] and nine botulinum toxin injections). POEM was scheduled.

The procedure was performed under general anesthesia, with the patient in the supine position. Longitudinal mucosal incision and submucosal tunneling were performed without incidence using a Hybrid Knife (ERBE Elektromedizin, Tübingen, Germany). However, when starting the myotomy, severe hypercarbia, subcutaneous emphysema, and hemodynamic instability with livedo reticularis occurred due to capnothorax and tension capnoperitoneum. Emergency therapeutic measures including percutaneous thoracic and abdominal needle decompression were performed and the patient was stabilized. Capnothorax was reabsorbed as confirmed by intraprocedural ultrasound, and the procedure was restarted.

To avoid gas-related complications, $\mathrm{CO}_{2}$ was switched off, room temperature sterile water was infused through the scope, and underwater myotomy was performed ( $\triangleright$ Video 1 ).

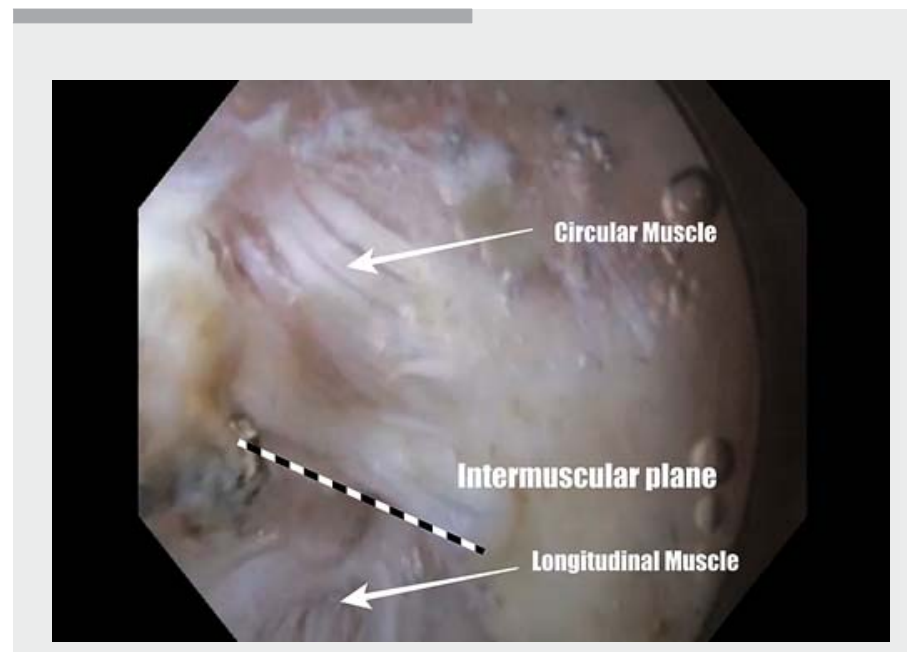

Video 1 Peroral endoscopic myotomy (POEM) complicated by tension capnoperitoneum and capnothorax when starting the myotomy. After percutaneous thoracic and abdominal needle decompression, the patient was stabilized and underwater POEM was performed to avoid complications.

A selective myotomy of the circular muscle fibers was completed including $2 \mathrm{~cm}$ of gastric myotomy. During myotomy more water irrigation was used to push the mucosa away from the myotomy plane and flush out bubbles generated by diathermy.

The patient was discharged after 5 days with no further complications. At 3-month follow-up, he had a normal diet with Eckardt score 0 .

Underwater POEM might be a good alternative in high-risk patients (severe COPD) as shown in this case.

Endoscopy_UCTN_Code_TTT_1AO_2AN

\section{Competing interests}

The authors declare that they have no conflicts of interest.
The authors

Hugo Uchima', Juan Colan ${ }^{1}$, Ingrid Marín ${ }^{1}$, Vicente Moreno ${ }^{1}$, Guillermo Larios ${ }^{2}$, Rachid Tazi $^{3}$, Jordi Serra ${ }^{4}$

1 Endoscopy Unit, Gastroenterology Department, Hospital Germans Trias i Pujol, Badalona, Barcelona, Spain

2 Anesthesiology Department, Hospital Germans Trias i Pujol, Badalona, Barcelona, Spain

3 Respiratory Diseases Department, Hospital Germans Trias i Pujol, Badalona, Barcelona, Spain

4 Motility Disorders Unit, Gastroenterology Department, Hospital Germans Trias i Pujol, Badalona, Barcelona, Spain

Corresponding author

\section{Hugo Uchima, MD}

Endoscopy Unit, Gastroenterology Department, Hospital Germans Trias i Pujol, Vilana 12 Planta - 1, Barcelona 08022, Spain Fax: +34-93-2279387

huchima.germanstrias@gencat.cat 
Bibliography

[1] Werner YB, Von Renteln D, Noder T et al. Early adverse events of per-oral endoscopic myotomy. Gastrointest Endosc 2017; 85: 708-718

[2] Binmoeller KF, Bhat YM. Underwater peroral endoscopic myotomy. Gastrointest Endosc 2016; 83: 454
Endoscopy 2020; 52: E396-E397

DOI 10.1055/a-1144-2547

ISSN 0013-726X

published online 17.4 .2020

(c) 2020. Thieme. All rights reserved.

Georg Thieme Verlag KG, Rüdigerstraße 14,

70469 Stuttgart, Germany

\section{ENDOSCOPY E-VIDEOS}

https:/|eref.thieme.de/e-videos

口回 Endoscopy E-Videos is a free 留 靣: on interesting cases and new techniques in gastroenterological endoscopy. All papers include a high quality video and all contributions are freely accessible online.

This section has its own submission website at

https://mc.manuscriptcentral.com/e-videos 